\title{
Analisis Hubungan Pengajaran dengan Mutu Pelayanan Rumah Sakit di Rumah Sakit Islam Kota Padang
}

\author{
M.Adharudin ${ }^{1 *}$, Yulastri Arif $^{2}$, Dorisnita $^{3}$ \\ ${ }^{1}$ Departemen Magister Keperawatan, Universitas Andalas \\ ${ }^{2,3}$ RSUP M. Djamil, Sumatera Barat \\ Correspondence email: m.adharudin@gmail.com ${ }^{1}$; yulastri.arif@gmail.com ${ }^{2}$; dorisnita@ymail.com ${ }^{3}$
}

\begin{abstract}
Abstrak. Mutu pelayanan rumah sakit adalah penilaian pelayanan yang diperoleh dari pasien dengan biaya efisien dan hasil dari kinerja organisasi rumah sakit. Persaingan pasar bebas menuntut kita meningkatkan mutu disemua bidang terutama dipelayanan kesehatan agar diakui secara internasional, fenomena masyarakat lebih memilih berobat ke luar negeri menjadi tantangan besar dalam peningkatan mutu pelayanan dirumah sakit. Tujuan penelitian ini untuk mengetahui hubungan Pengajaran dengan mutu pelayanan rumah sakit di rumah sakit islam Kota Padang. Desain penelitian yang digunakan adalah deskriptif korelasi dengan rancangan cross sectional. Sampel penelitian ini sebanyak 325 pasien rawat inap. Hasil penelitian ini membuktikan bahwa terdapat hubungan antara pengajaran dengan mutu pelayanan rumah sakit di RSI Kota Padang $(\mathrm{P}=0,006)$. Penelitian ini merekomendasikan rumah sakit untuk meningkatnya peran aktif perawat dalam meningkatkan mutu pelayanan dengan pendekatan model COPA yaitu pengajaran yang dapat diaplikasikan di rumah sakit.
\end{abstract}

Kata Kunci: Mutu Pelayanan; Model COPA; Pengajaran.

\begin{abstract}
Hospital service quality is an assessment of services obtained from patients with cost-efficient and results from the organization's organizational performance. Free market competition requires us to improve quality in all fields, especially in health services to be recognized internationally, the phenomenon of people prefering to seek treatment abroad is a big challenge in improving the quality of hospital services. The purpose of this study was to determine the relationship of Teaching with the services quality in Padang City Islamic hospitals. The study design used was descriptive correlation with cross sectional design. The sample of this study were 325 inpatients. The results of this study prove that there is a relationship between teaching and service quality in Padang City Islamic hospitals $(P=0.006)$. This study recommends hospitals to increase the active role of nurses in improving service quality with the COPA model approach, which is teaching that can be applied in hospitals.
\end{abstract}

Keyword: Service Quality; Model COPA; Teaching.

\section{PENDAHULUAN}

Mutu pelayanan adalah hasil penilaian organisasi yang menyediakan layanan efektif untuk mempromosikan dan mencapai kepuasan pasien (Asefzadeh, et al. 2016). Menurut Damopolii, et al. (2018) mutu pelayanan adalah untuk mengukur kebutuhan pasien dari pemberian jasa guna mengetahui kebutuhan yang akan diperoleh dengan biaya efisien. Sedangkan menurut Zarei, et al. (2014) mutu pelayanan adalah kepercayaan pasien kepada pihak rumah sakit terhadap penyediaan layanan terbaik. Jadi, mutu pelayanan rumah sakit adalah penilaian yang diperoleh dari kepuasan pasien dengan biaya efisien dan menjadi hasil dari kinerja organisasinya.

Menurut Haning (2017) Persaingan pasar bebas menuntut kita meningkatkan mutu disemua bidang terutama pada kualitas pelayanan kesehatan agar diakui secara internasional, Fenomena masyarakat lebih memilih berobat ke luar negeri menjadi tantangan besar dalam peningkatan mutu pelayanan. Hasil penelitian Wattimena (2014) didapatkan kualitas pelayanan dinilai kurang memuaskan sehingga terjadi arus peningkatan pengobatan ke luar negeri, meskipun ilmu dan teknologi dalam bidang kesehatan di Indonesia tidaklah jauh berbeda dibandingkan dengan keadaan di luar negeri.
Hal ini membuat uang warga negara Indonesia diperkirakan habis Rp.100Triliun per tahun hanya untuk berobat keluar negeri (Grehenson, 2011).

Adapun Kebijakan yang tepat untuk meningkatkan mutu pelayanan dirumah sakit dari Undang-undang Republik Indonesia Nomor 44 Tahun 2009, tujuan penyelenggaraan rumah sakit yaitu meningkatkan mutu pelayanan kesehatan serta memberikan kepastian hukum kepada pasien. Hal ini juga selaras dengan program World Health Organization (WHO) yaitu negara menjamin seluruh warganya untuk mendapatkan pelayanan kesehatan yang bermutu (Handayani, et al. 2015). Maka, mutu pelayanan merupakan kegiatan pelayanan yang harus dicapai oleh setiap penyelenggara pelayanan kesehatan. Oleh karena itu rumah sakit harus menetapkan indikator mutu setiap pelayanan yang dilaksanakan yang telah ditetapkan.

Kualitas layanan dapat dirasakan dan diukur dengan pengembangan dimensi model pengukuran mutu layanan yang memiliki dampak signifikan pada kepuasan layanan dirumah sakit sehingga memberikan layanan berkualitas dan mempertahankan daya saing (Thawesaengskulthai, et al, 2015). Jadi pengukuran mutu pelayanan sangat penting dilakukan untuk melihat kepuasan pengguna layanan kesehatan. Pengukuran 
kepuasan pasien dengan pengukuran dimensi mutu layanan.

Keberadaan perawat sebagai pemberi pelayanan sangatlah penting, karena masyarakat yang modern menuntut professionalisme perawat dalam pelaksanaan tugasnya (Rantung, 2018). Di Cina, pengaruh kompetensi perawat sampai terjadi pada serangan fisik ke penyedia layanan sehingga peningkatan kepuasan pasien ini dapat mengurangi perselisihan juga mendukung peningkatan kompetensi penyedia layanan (Tang, et al. 2018). Maka, kompetensi perawat sangat penting sesuai mutu layanan agar tidak terjadinya kontak fisik ke penyedia layanan dan tercapainya mutu layanan yang baik. Kompetensi perawat juga dapat mengacu kepada model competency outcome and performance assesment.

Menurut Lenburg, et al. (2009), Competency Outcomes and Performance Assessment Model (Model COPA) adalah teori kerangka kerja kurikulum untuk mempersiapkan peserta didik berperan kinerja yang efektif, perilaku klinis komprehensif dan bukti yang kompeten. Sedangkan hasil penelitian $\mathrm{Ha}$ and Nuntaboot, (2016); Kahya and Oral, (2018), penilaian kinerja dan kompetensi perawat sangat penting terhadap perawatan klinik demi keamanan praktik keperawatan dalam mencapai kualitas layanan. Maka Model COPA adalah kerangka kerja untuk mempersiapkan perawat berperan efektif, komprehensif dan kompeten demi keamanan dan kualitas pelayanan. Oleh karena itu perlu ada acuan penilaian dari model COPA tersebut yang terdiri dari delapan dimensi kompetensi keterampilan perawat.

Adapun delapan kompetensi keterampilan Model COPA sangat sederhana, namun komprehensif, yaitu: Assessment and Intervention, Communication, Critical Thinking, Human Caring and Relationship, Management, Leadership. Teaching, dan Knowledge Integration (Lenburg, et, al, 2009). Hasil penelitian Pihlainen, et al. (2017) mengatakan perlunya pendekatan lebih terhadap penilaian individual kompetensi manajemen dan kepemimpinan dari segi perspektif holistik bukan berdasarkan posisi profesinya. Begitu juga hasil penelitian Kim (2016), didapatkan korelasi yang positif antara kompetensi komunikasi dan berpikir kritis terhadap peningkatan kemampuan kinerja klinis. Jadi, delapan kompetensi keterampilan Model COPA sangatlah diperlukan penilaian untuk peningkatan kemampuan kinerja.

Menurut Lenburg, et, al. (2009) Model COPA menawarkan arah yang jelas untuk evaluasi standard kompetensi pencapaian hasil yang diverifikasi oleh pemeriksa kinerja, meningkatkan kompetensi klinis dan kepercayaan diri seseorang. Filosofi COPA juga mendorong perubahan penting untuk melanjutkan pengembangan kompetensi ditempat yang lebih penting dari pada sebelumnya untuk memastikan pasien lebih aman. Maka model COPA sangat baik jika digunakan ditatanan klinis.

Wawancara dilakukan peneliti pada 10 pasien rawat inap di RSI Kota Padang didapatkan bahwa kualitas pelayanan yang diberikan belum baik. 8 dari 10 pasien mengatakan perawat belum melaksanakan promosi kesehatan bagi pasien dirawat inap disebabkan karena keterbatasan waktu yang dimiliki bersama perawat. 7 dari 10 pasien mengatakan perawatnya tidak memberikan pendidikan kesehatan padanya bagaimana tentang penanganan penyakit yang diderita pasien.

Berdasarkan survey yang telah dilakukan peneliti cukup mewakili dari delapan item model COPA juga merupakan faktor yang akan diteliti untuk mengetahui mutu pelayanan dirumah sakit menggunakan pendekatan model COPA ini dapat diterapkan: pengajaran agar diterapkan dan terjalin antar perawat dan tenaga kesehatan lain merupakan faktor yang mempengaruhi, agar tidak tidak terjadi keluhan mengenai sikap dan tindakan perawat terhadap pasien selama menerima pelayana dirumah sakit.

Sementara itu, mutu pelayanan kalau tidak segera ditindak lanjuti dan berlangsung terus menerus dalam jangka waktu yang lama akan mengakibatkan ketidakpuasaan dan menurunnya jumlah kunjungan pasien di rumah sakit. Mengacu pada permasalahan diatas perlu dilakukan "Analisis hubungan pengajaran dengan mutu pelayanan rumah sakit di Rumah Sakit Islam Kota Padang.

\section{METODE}

Desain penelitian yang digunakan adalah deskriptif korelasi dengan rancangan Cross Sectional. Penelitian ini bertujuan untuk diketahuinya Hubungan Pengajaran dengan Mutu Pelayanan Rumah Sakit di Rumah Sakit Islam Kota Padang. Populasi penelitian adalah seluruh pasien rawat inap di 3 RSI Kota Padang yang terdiri dari RSI Ibnu Sina, RSI Siti Rahma dan RSU Aisyiyah. Teknik pengambilan sampel yang digunakan pada penelitian ini adalah Probability random Sampling. Sampel yang digunakan dalam penelitian ini sebanyak 325 responden. Data dikumpulkan dengan menggunakan kuesioner karakteristik responden. Selain itu juga terdapat kuesioner Model COPA yaitu Pengajaran

\section{HASIL DAN PEMBAHASAN}

Tabel 1. Distribusi Frekuensi Karakteristik Responden berdasarkan Jenis Kelamin, Umur, Pendidikan Terakhir, Dan Pekerjaan $(\mathrm{n}=325)$

\begin{tabular}{lll}
\hline Karakteristik & $\boldsymbol{f}$ & $\mathbf{\%}$ \\
\hline Jenis Kelamin & & \\
- Laki-laki & 192 & 59,1 \\
- Perempuan & 133 & 40,9 \\
Umur & & \\
- Dewasa Muda (18-40) & 237 & 72,9 \\
- Dewasa Tua (>41) & 88 & 27,1
\end{tabular}




\section{Pendidikan}

- Tamat SD

- Tamat SMP

- Tamat SMA

- Sarjana/Perguruan Tinggi

Pekerjaan

- Petani, Wiraswasta, Pedagang

- PNS/TNI/Polri/Pensiunan

- Pelajar/Mahasiswa

- IRT

Tabel 1 menunjukkan lebih dari setengah pasien berjenis kelamin laki-laki dan berumur dewasa muda, sedangkan kurang dari setengahnya berpendidikan tamat SMA dengan pekerjaan swasta.

Tabel 2. Distribusi Frekuensi Pengajaran dan Mutu Pelayanan Rumah Sakit di RSI Kota Padang tahun 2019 ( $\mathrm{n}=325)$

\begin{tabular}{llll}
\hline Variabel & Kriteria & F & \% \\
\hline Mutu Pelayanan & Tidak Bermutu & 74 & 22,8 \\
& Bermutu & 251 & 77,2 \\
Pengajaran & Tidak Baik & 65 & 20.0 \\
& Baik & 260 & 80.0 \\
\hline
\end{tabular}

Tabel 2 menunjukkan bahwa dari 325 responden menyatakan sebagian besar mutu pelayanan bermutu $(77,2 \%)$, dan sebagian besar pengajaran baik $(80,0 \%)$,

Tabel 3. Hubungan Pengajaran dengan Mutu Pelayanan Rumah Sakit di RSI Kota Padang Tahun $2019(\mathrm{n}=325)$

\begin{tabular}{|c|c|c|c|c|c|c|c|c|c|}
\hline \multirow{3}{*}{ Variabel } & \multirow{3}{*}{ Kriteria } & \multicolumn{4}{|c|}{ Mutu Pelayanan } & & & \multirow{3}{*}{$\begin{array}{l}\mathbf{P} \\
\text { Value }\end{array}$} & \multirow{3}{*}{$\begin{array}{l}\text { OR } \\
\text { (CI 95\%) }\end{array}$} \\
\hline & & \multicolumn{2}{|c|}{ Tidak Bermutu } & \multicolumn{2}{|c|}{ Bermutu } & \multicolumn{2}{|c|}{ Jumlah } & & \\
\hline & & $\mathrm{f}$ & $\%$ & $\mathrm{f}$ & $\%$ & $\mathrm{f}$ & $\%$ & & \\
\hline \multirow[t]{2}{*}{ Pengajaran } & Tidak Baik & 6 & 9,2 & 59 & 90,8 & 65 & 100 & \multirow[t]{2}{*}{0,006} & \multirow[t]{2}{*}{0,287} \\
\hline & Baik & 68 & 26,2 & 192 & 73,8 & 260 & 100 & & \\
\hline
\end{tabular}

Tabel 3. menunjukkan bahwa dari terdapat hubungan signifikan antara pengajaran dengan mutu pelayanan rumah sakit di RSI Kota Padang ( -value = 0,006).

\section{Pembahasan}

\section{Gambaran Karakteristik Responden}

Berdasarkan tabel 1 hasil penelitian memperlihatkan bahwa lebih dari setengahnya responden berjenis kelamin laki-laki dengan persentase $59,1 \%$ dan yang berjenis kelamin perempuan sebanyak 40,9\%. Beberapa hasil penelitian menunjukkan bahwa ada korelasi antara jenis kelamin dengan mutu pelayanan. Menurut Zaghloul et al (2005) mengemukakan bukti hubungan antara gender dan mutu pelayanan kesehatan. Wanita lebih puas dengan layanan kesehatan daripada pria. Sebaliknya penelitian menyimpulkan bahwa pria memiliki penliaian mutu layanan yang lebih tinggi skornya pada asuhan keperawatan, kenyamanan, kunjungan, dan kebersihan daipada wanita. Selain itu hasil penelitian secara umum menyarankan bahwa pasien lebih memilih tenaga kesehatan dari gender yang sama.

Hal ini sejalan dengan penelitian yang dilakukan oleh Bikker dan Thompson (2006) dimana wanita lebih cenderung mengekspresikan kepuasan yang tinggi dibanding dengan laki-laki dan jenis kelamin memberikan prediksi penting pada pasien yang mendapat pelayanan kesehatan. Disamping itu menurut Dorieke et al (2009) dalam penelitiannya mengungkapkan bahwa jenis kelamin memiliki efek yang signifikan terhadap kepuasan dilihat dari beberapa dimensi, tetapi efek ini lemah dan tidak konsisten.

\section{Pengajaran dalam Mutu Pelayanan Rumah Sakit di RSI Kota Padang}

Berdasarkan hasil penelitian diketahui bahwa lebih dari sebagian besar mutu pelayanan bermutu $(77,2 \%)$, dan sebagian besar pengajaran baik $(80,0 \%)$ di RSI Kota Padang. didapatkan hasil penelitiannya bahwa ada hubungan yang signifikan antara perawat sebagai educator dengan kebutuhan rasa aman.

Perawat sebagai pendidik berperan dalam mengajarkan ilmu kepada individu, keluarga, masyarakat dan tenaga kesehatan (Sudarman, 2008). Perawat menjalankan perannya sebagai pendidik dalam upaya untuk meningkatkan kesehatan melalui perilaku yang menunjang kesehatannya (Asmadi, 2008). Perawat sebagai pendidik harus mempunyai kemampuan untuk mengkaji kekuatan dan akibat yang ditimbulkan dari pemberi informasi dan perilaku yang diinginkan oleh individu (Nursalam, 2008).

Menurut analisis peneliti, perawat yang bertugas harus meningkatkan pegetahuannnya pasiennya tentang terkait derajat kesehatan pasien. Dengan diberitahunya pasien tentang derajat kesehatan pasien, maka akan dapat menjadikan perawat pengajara lebih memahami kondisi yang sedang dialami oleh pasien. Berdasarkan hal tersebut maka peneliti menyarankan agar pihak rumah sakit dapat membuat penjadwalan waktunya perawat melakukan pengajaran terhadap pasiennya mengenai derajat kesehatan pasien minimal 1 bulan sekali diruangannya. Upaya peningkatan skill perawat mengedukasi pasiennya dapat berupa pengadaan kegiatan penyuluhan dari perawat kepada pasiennya tentang derajat kesehatan pasien untuk peningkatan mutu layanan rumah sakit tersebut yang langsung dirasakan oleh pasien yang berobat. 


\section{Hubungan Pengajaran Dengan Mutu Pelayanan Di RSI Kota Padang}

Berdasarkan hasil penelitian yang telah dilakukan oleh peneliti diketahui bahwa dari 260 responden yang menyatakan pengajaran dengan mutu pelayanan baik, sebanyak $73,8 \%$ menyatakan pengajaran bermutu dan sebanyak $26,2 \%$ juga responden menyatakan tidak bermutu. Sedangkan dari 65 respoden yang menyatakan pengajaran tidak baik, sebanyak 90,8,0\% responden yang menyatakan pengajaran bermutu dan $9,2 \%$ juga responden menyatakan tidak bermutu.

Berdasarkan uji statistik menggunakan uji chi square didapati $\mathrm{p}$ value $0,006<0,05$ yang berarti bahwa ada hubungan yang bermakna antara pengajaran dengan mutu pelayanan rumah sakit di RSI Kota Padang.

Penelitian yang sama disampaikan oleh Hapsari (2013) tentang hubungan perawat sebagai educator dengan pemenuhan kebutuhan rasa aman pasien, didapatkan hasil penelitiannya bahwa ada hubungan yang signifikan antara perawat sebagai educator dengan kebutuhan rasa aman. Perawat sebagai pendidik harus mempunyai kemampuan untuk mengkaji kekuatan dan akibat yang ditimbulkan dari pemberi informasi dan perilaku yang diinginkan oleh individu (Nursalam, 2008). Pasien dan keluarga seringkali bertanya kepada perawat tentang hal-hal yang berkaitan dengan kondisinya pasien. Pasien mungkin akan menanyakan tentang tindakan keperawatan yang dilakukan kepadanya dan menannyakan rasa nyeri yang timbul. Perawat sebaiknya berusaha untuk mengantisipasi kebutuhan pasien dan keluarganya tentang informasi yang diperlukan terkait peningkatan kesehatan pasien. Peningkatan kesehatan pasien dengan pengajaran yang efektif kepada pasien. Pengajaran yang efektif yaitu perawat dapat mengetahui kapan waktu yang tepat untuk memberikan pengajaran dan menentukan apa yang perlu pasien ketahui (Potter \& Perry, 2005).

Berdasarkan hal tersebut maka peneliti menyarankan agar pihak rumah sakit dapat membuat penjadwalan waktunya perawat melakukan pengajaran terhadap pasiennya mengenai derajat kesehatan pasien minimal 1 bulan sekali diruangannya. Upaya peningkatan skill perawat mengedukasi pasiennya dapat berupa pengadaan kegiatan penyuluhan dari perawat kepada pasiennya tentang derajat kesehatan pasien untuk peningkatan mutu layanan rumah sakit tersebut yang langsung dirasakan oleh pasien yang berobat.

\section{SIMPULAN}

Karakteristik pasien rawat inap di RSI Kota Padang lebih dari setengah pasien berjenis kelamin lakilaki dan berumur dewasa muda, sedangkan kurang dari setengahnya berpendidikan tamat SMA dengan pekerjaan swasta. Sebagian besar responden menyatakan pengajaran baik. Sebagian besar responden menyatakan mutu pelayanan rumah sakit bermutu.

Meningkatkan pelayanan melalui pelayanan pengajaran yang dapat diaplikaikan ke pasien rawat inap dan menambahkan keilmuan terutama dalam mengembangkan metode pelayanan yang lebih dapat memuaskan pasien.

\section{DAFTAR PUSTAKA}

Asefzadeh, S., Gholami, S., Rajaee, R., Najafi, M., \& Alijanzadeh, M. (2016). Evaluation of the Quality of Health Service Providers: The Iranian People Perspective 2014. 8(March), 2073-2080. https://doi.org/10.19082/2073

Damopolii, s. H., tucunan, a. A. T., \& maramis, f. R. R. (2018). Hubungan antara mutu jasa pelayanan kesehatan dengan kepuasan pasien rawat inap di rs bhayangkara tk iii manado. Jurnal kesmas, vol. 7 no. 5., 7(5).

Ha, D. T., \& Nuntaboot, K. (2016). Actual Nursing Competency among Nurses in Hospital in Vietnam. 10(3), 1013-1020.

Handayani, P. W., Hidayanto, A. N., Sandhyaduhita, P. I., Kasiyah, \& Ayuningtyas, D. (2015). Strategic hospital services quality analysis in Indonesia. Expert Systems with Applications, 42(6), 30673078. https://doi.org/10.1016/j.eswa.2014.11.065

Indonesia, U. R. (2009). Undang-Undang No. 44 Tentang Rumah Sakit Tahun 2009.https://doi.org/10.1017/CBO9781107415324 .004

Kahya, E., \& Oral, N. (2018). Measurement of clinical nurse performance: Developing a tool including contextual items. Journal of Nursing Education and Practice, $8(6), \quad 112$. https://doi.org/10.5430/jnep.v8n6p112

Kim, M.-O. (2016). Study on Self-efficacy, Communication competency, Critical thinking disposition and Clinical performance ability of nursing students. Journal of the Korea AcademiaIndustrial Cooperation Society, 17(6), 609-617. https://doi.org/10.5762/kais.2016.17.6.609

Lenburg, C. B., Abdur-rahman, V. Z., \& Klein, C. J. (2009). Implementing the COPA Model $290 \mathrm{~N} \mathrm{u}$ r s i n g E d u a t i o n Pers pe ctive s. October, 0-7.

Pihlainen, V., Kivinen, T., \& Lammintakanen, J. (2017). Management and Leadership Competence in Hospital: a Systematic Literature Review. 2-7. https://doi.org/10.1108/LHS-11-2014-0072

Rantung, G. (2018). PATIENT PERCEPTION OF NURSES ' PROFESSIONAL COMPETENCIES. (November).

Tang, C., Tian, B., Zhang, X., Zhang, K., Xiao, X., Simoni, J. M., \& Wang, H. (2018). The influence of cultural competence of nurses on patient satisfaction and the mediating effect of patient 
trust. Journal of Advanced Nursing, (January 2018), 749-759. https://doi.org/10.1111/jan.13854

Thawesaengskulthai, N., Wongrukmit, P., \& Dahlgaard,

J. J. (2015). Hospital service quality measurement models: patients from Asia, Europe, Australia and America. Total Quality Management and Business Excellence, 26(9-10), 1029-1041. https://doi.org/10.1080/14783363.2015.1068596

Zarei, E., Daneshkohan, A., Khabiri, R., \& Arab, M. (2014). The Effect of Hospital Service Quality on Patient's Trust. Iranian Red Crescent Medical Journal, 17(1), 1-5. https://doi.org/10.5812/ircmj.17505 